\title{
Exploring the Potential Impacts of Climate Variability on Spring Wheat Yield with the APSIM Decision Support Tool
}

\author{
Louis Kouadio', Nathaniel Newlands², Andries Potgieter ${ }^{3}$, Greg McLean ${ }^{4}$, Harvey Hill5 \\ ${ }^{1}$ International Centre for Applied Climate Sciences, University of Southern Queensland, Toowoomba, Australia \\ ${ }^{2}$ Science and Technology (S \& T), Environmental Health, Agriculture and Agri-Food Canada (AAFC), Lethbridge \\ Research Centre, Lethbridge, Canada \\ ${ }^{3}$ Queensland Alliance for Agriculture and Food Innovation, University of Queensland, Toowoomba, Australia \\ ${ }^{4}$ Queensland Department of Agriculture and Fisheries, Toowoomba, Australia \\ ${ }^{5}$ National Agroclimate Information Service, S \& T-AAFC, Saskatoon, Canada \\ Email: Amani.Kouadio@usq.edu.au
}

Received 26 June 2015; accepted 19 July 2015; published 22 July 2015

Copyright (C) 2015 by authors and Scientific Research Publishing Inc.

This work is licensed under the Creative Commons Attribution International License (CC BY).

http://creativecommons.org/licenses/by/4.0/

(c) (i) Open Access

\section{Abstract}

Assessing the impacts of climate variability on agricultural productivity at regional, national or global scale is essential for defining adaptation and mitigation strategies. We explore in this study the potential changes in spring wheat yields at Swift Current and Melfort, Canada, for different sowing windows under projected climate scenarios (i.e., the representative concentration pathways, RCP4.5 and RCP8.5). First, the APSIM model was calibrated and evaluated at the study sites using data from long term experimental field plots. Then, the impacts of change in sowing dates on final yield were assessed over the 2030-2099 period with a 1990-2009 baseline period of observed yield data, assuming that other crop management practices remained unchanged. Results showed that the performance of APSIM was quite satisfactory with an index of agreement of $0.80, R^{2}$ of 0.54, and mean absolute error (MAE) and root mean square error (RMSE) of $529 \mathrm{~kg} / \mathrm{ha}$ and 1023 $\mathrm{kg} / \mathrm{ha}$, respectively (MAE $=476 \mathrm{~kg} / \mathrm{ha}$ and $\mathrm{RMSE}=684 \mathrm{~kg} / \mathrm{ha}$ in calibration phase). Under the projected climate conditions, a general trend in yield loss was observed regardless of the sowing window, with a range from $-24 \%$ to $-94 \%$ depending on the site and the RCP, and noticeable losses during the 2060s and beyond (increasing $\mathrm{CO}_{2}$ effects being excluded). Smallest yield losses obtained through earlier possible sowing date (i.e., mid-April) under the projected future climate suggested that this option might be explored for mitigating possible adverse impacts of climate variability. Our findings could therefore serve as a basis for using APSIM as a decision support tool for adaptation/mitigation options under potential climate variability within Western Canada. 


\section{Keywords}

\section{Climate Variability, APSIM, Crop Modelling, Spring Wheat}

\section{Introduction}

Adapting agricultural systems and mitigating the potential adverse effects of anticipated, future climate variability has become more important than ever in the context of global climate changes. Decision support tools are often used for agricultural/agroclimate risk management. They generally rely on modelling approach including biophysical process-based crop growth models (field to regional or global scale models) [1]. Although they are a simplification of more complex and interconnected soil-plant-atmosphere systems, crop growth models (point to global scale models) with satisfactory performance are increasingly used to evaluate various aspects (e.g., magnitude and pattern) of the impacts of climate variability on agricultural productivity [2]-[7]. However, several differences exist in crop modelling frameworks because of their parameterization, their implementation at specific spatial scales, their sensitivity to input data (availability, temporal and spatial scales), etc. Indeed, their use within agricultural sustainability decision-making frameworks can also be challenging by the variability in leading metrics (e.g., yield) used for their calibration/training [8]. Given the difficulties to apply models to generate real solutions for the agricultural sector, various joint modelling initiatives (e.g., AgMIP, http://www.agmip.org/) have emerged since the 2000s to face the increasing challenges in agricultural modelling and explore adaptation options for improving global food security and agricultural sustainability in a changing climate condition. Moreover, within such joint initiatives several models are selected and inter-compared depending on, e.g. the crop targeted, the capacity of the model to simulate major crop growth and development processes, and the ability of the model to be implemented in decision support framework for addressing real-world problems [9]-[11]. From such initiatives benchmarks are defined and consensual approaches are proposed to improve our understanding on models capabilities to help in decision making. Examples of models' intercomparison include the pilot study involving 27 wheat process-based models [11], which is performed in order to assess the responses to variability of $\mathrm{CO}_{2}$ concentration, temperatures, rainfall, and some management practices at four sentinel sites around the world (representing variation in wheat productivity).

Canada is one of the top wheat producers in the world, with a production of circa 37.5 million metric tons in 2013 [12]. Studies based on process-based models simulations and dealing with the evaluation of the impacts of climate variability on spring wheat production in Canadian agricultural landscape have been carried out. Touré et al. (1995) [13] compared four wheat simulation models including the CERES (Crop Estimation through Resources and Environment Synthesis; [14], EPIC (Erosion Productivity Impact Calculator; [15]), Stewart [16] and Sinclair [17] models, for evaluating the impact of climate change on dryland spring wheat yield in southern Alberta. Artificial climate parameters and scenarios derived from the Canadian Climate Centre second generation general circulation model [18] were used as climate inputs in their study. He et al. (2012) [5] used the CERESWheat in DSSAT (Decision Support System for Agrotechnology Transfer; [6]) to investigate the earliness of seeding dates of spring wheat under projected climate conditions in Saskatchewan. Qian et al. (2015) [19] also employed the same model for assessing spring yield changes under future climate scenarios across the Canadian Prairies (i.e., the main spring wheat growing region in Canada). In both studies, future climate conditions were based on the IPCC SRES forcing scenarios [20], A2 in [19], and A2, A1B and B1 in [5]. Yet, other processbased crop growth models that have gained in popularity during the last decade have not been tested in Canadian conditions. This includes the Agricultural Production Systems Simulator (APSIM), which is a modular modelling framework that has been developed to simulate biophysical process in farming systems, in particular where there is interest in the economic and ecological outcomes of management practice in the face of climatic risk [7]. APSIM modules include a diverse range of crops and pastures, soil processes (including water balance, $\mathrm{N}$ and $\mathrm{P}$ transformations, and soil erosion), and a full range of management controls.

Although evaluating the impacts of climate variability on agricultural production at global scale is essential [21], studies across individual sites in regions are still worthwhile since assessing these impacts in most vulnerable regions (i.e., sub-tropic regions), as well as in major cereal grains producer countries (cereal grains being staple food worldwide), is of particular interest for food security, trade, and geopolitical stability. The aim of this 
study is to explore the changes in spring wheat yield under future climate conditions using the APSIM model. First, the ability of APSIM to represent the temporal variability in spring wheat at selected sites in western Canada was tested. Then, the trends of wheat yields were assessed through different management practices in APSIM (i.e., variation of sowing dates), with input climate data derived from the representative concentration pathways (RCPs) of important greenhouse gases forced with concentrations following the medium emission scenario (RCP4.5) and the high emission scenario (RCP8.5).

\section{Materials and Methods}

\subsection{Study Area and Data Sources}

Two sites located in the Province of Saskatchewan in Western Canada [Swift Current $\left(107^{\circ} 48^{\prime} \mathrm{W}, 50^{\circ} 17^{\prime} \mathrm{N}\right)$, and Melfort $\left.\left(104^{\circ} 36^{\prime} \mathrm{W}, 52^{\circ} 52^{\prime} \mathrm{N}\right)\right]$ were considered. The yield data of the selected sites originated from Agriculture and Agri-Food Canada (AAFC)'s experimental plots at these locations. Data spanned a $>20$-year period at each site over 1946-2009 (Table 1), with three main wheat cultivars grown during this period (Marquis, Neepawa, and Barrie).

Historical climate data (i.e., daily minimum and maximum temperatures, and precipitation) originated from weather stations and were provided by Environment Canada and other partner institutions through the Drought Watch program (http://www.agr.gc.ca/pfra/drought/index e.htm). The data period (referred to as historical period) was set according to the available wheat yield data (1949-2009 and 1961-2009 for Swift Current and Melfort, respectively). Daily solar radiation over these periods was generated using the SolarCalc model [22]. This model has been proven useful for estimating the daily incoming solar radiation in western Canadian conditions [23]. SolarCalc produces hourly incoming solar radiation. Therefore, the outputs were summed up to obtain the daily values in our study. The input data required for SolarCalc runs include latitude, longitude, and elevation of the site, along with daily minimum and maximum air temperatures, and precipitation.

Climate scenarios from the Canadian fourth generation Regional Climate Model (CanRCM4) driven by the second generation Canadian Earth System Model (CanESM2) at $0.22^{\circ}$ horizontal grid resolution (approximately $25 \mathrm{~km}$ ) were considered in this study. The CanRCM4 model is a "limited-area version" of the CanAM4 (Canadian Atmospheric global climate Model), developed by the CCCma/EC. A detailed description of its underlying physical processes can be found in [24] [25]. The climate general circulation model CanESM2 combines the fourth generation Atmospheric General Circulation Model (CanCM4) and the terrestrial carbon cycle based on the Canadian Terrestrial Ecosystem Model (CTEM), including thus dynamic vegetation in its computation [26] [27]. It is one of the models from the CMIP5 (Coupled Model Intercomparison Project Phase 5) that were considered in the Intergovernmental Panel on Climate Change (IPCC) 5th Assessment Report [28]. The future climate scenarios data (2030-2099 period) were calculated based on the representative concentration pathways of major contributing greenhouse gases (i.e., those with significant radiative potentials), forced with concentrations following the medium emission scenario (RCP4.5) and the high emission scenario (RCP8.5). They were downloaded from the Canadian Centre for Climate Modelling and Analysis division of Environment Canada website (CCCma/EC; http://www.ec.gc.ca/ccmac-cccma/).

Table 1. Data period for spring wheat yield from the Agriculture and Agri-Food Canada's experimental plots at Swift Current and Melfort, Canada.

\begin{tabular}{|c|c|c|c|}
\hline Site & Soil Type & Wheat Cultivar & Data Period \\
\hline \multirow[t]{3}{*}{ Swift Current } & Orthic Brown Chernozem & Marquis & $1949-1965$ \\
\hline & & Neepawa & 1966-1997 \\
\hline & & AC Barrie & 1998-2009 \\
\hline \multirow[t]{3}{*}{ Melfort } & Orthic Black Chernozem & Marquis & 1946-1964 \\
\hline & & Neepawa & $1965-1973$ and $1995-2000$ \\
\hline & & AC Barrie & 2001-2009 \\
\hline
\end{tabular}




\subsection{Configuration of Simulations}

A two-step procedure was used to test the APSIM model. This included 1) a sensitivity analysis to determine wheat parameters requiring most careful definition, and 2) a robustness test using reported yield data at the study sites. The calibration of the crop parameters was carried out based on the default values of an Australian wheat cultivar (i.e., Hartog). Data from a 4-year experimental study (1998-2001) near Swift Current [29] were used for this purpose. Crop management practices were set as per [29]: the sowing density, sowing depth and row spacing were 200 plants $/ \mathrm{m}^{2}, 30 \mathrm{~mm}$, and $230 \mathrm{~mm}$, respectively; a concentration of $112 \mathrm{~kg} \mathrm{~N} / \mathrm{ha}$ as ammonium sulphate was applied at sowing as urea fertilizer. Soil properties (Table 2) were retrieved from [29] [30]. The variety was sown when rainfall was at least $20 \mathrm{~mm}$ over the 10 previous days and the water content in the first top soil layer $(0-15 \mathrm{~cm})$ was assumed to be $>70 \%$ of plant available water. The sowing window considered spanned 26 April (earliest possible date) to 31 May (latest possible date). Planting dates were therefore simulated by the model based on the criteria mentioned.

A range of values of each of the crop parameters above and below those reported in the literature was run in APSIM, while keeping parameters other than the one being tested held constant. The most sensitive crop parameters were found to be thermal times during the vegetative, flowering and grain filling periods, and sensitivities to vernalisation and photoperiod. These parameters were then fine-tuned using data derived from experimental plots [29], which included grain yield, total above-ground biomass, and the anthesis and physiologic maturity dates. Next, the performance of the APSIM model (i.e., test of the model ability to predict yield interannual variability) was evaluated using historical climate and yield data. Note that data used for model training were not included.

All the simulations over the study period (historical and future) were performed using the previous settings at the two sites. In order to exclude the "carry-over" effects from previous seasons, soil $\mathrm{N}$ and water contents were reset every year in autumn (i.e., 31 October). The main differences in configuration settings between sites included the soil physico-chemical properties, soil plant water available capacity (PAWC), nitrogen content in soil layers (Table 2). No increasing $\mathrm{CO}_{2}$ effects were considered for simulations under future climate scenarios.

\subsection{Sensitivity Analysis for Future Climate Conditions and Data Analysis}

In order to assess what might be the effects on the future climate variability at each of the two sites, the impacts of varying sowing windows on grain yield were explored. The sowing date has been reported as one the sensitive parameters influencing spring wheat grain yield in the study region [31]. A combination of four possible earliest

\begin{tabular}{|c|c|c|c|c|c|c|c|c|c|c|c|c|c|c|c|}
\hline & \multicolumn{8}{|c|}{ Physical Parameters } & \multicolumn{4}{|c|}{ Chemical Parameters } & \multicolumn{3}{|c|}{$\begin{array}{l}\text { Soil Water-Related } \\
\text { Parameters for Wheat }\end{array}$} \\
\hline & $\begin{array}{l}\text { Depth } \\
(\mathrm{cm})\end{array}$ & $\begin{array}{l}\mathrm{BD} \\
(\mathrm{g} / \mathrm{cc})\end{array}$ & $\begin{array}{c}\text { LL15 } \\
(\mathrm{mm} / \mathrm{mm})\end{array}$ & $\begin{array}{c}\text { DUL } \\
(\mathrm{mm} / \mathrm{mm})\end{array}$ & $\begin{array}{c}\mathrm{SAT} \\
(\mathrm{mm} / \mathrm{mm})\end{array}$ & $\begin{array}{l}\text { Sand } \\
(\%)\end{array}$ & $\begin{array}{l}\text { Silt } \\
(\%)\end{array}$ & $\begin{array}{l}\text { Clay } \\
(\%)\end{array}$ & $\mathrm{F}_{\text {biom }}$ & $\mathrm{F}_{\text {inert }} \mathrm{t}$ & $\begin{array}{c}\mathrm{EC} \\
(1: 5 \mathrm{dS} / \mathrm{m})\end{array}$ & $\mathrm{pH}$ & $\begin{array}{c}\mathrm{LL} \\
(\mathrm{mm} / \mathrm{mm})\end{array}$ & $\begin{array}{c}\text { PAWC } \\
(\mathrm{mm} / \mathrm{mm})\end{array}$ & $\begin{array}{c}\mathrm{KL} \\
\left(\text { day }^{-1}\right)\end{array}$ \\
\hline \multirow[t]{5}{*}{$\begin{array}{l}\text { Swift } \\
\text { Current }\end{array}$} & $0-15$ & 1.22 & 0.09 & 0.29 & 0.34 & 32 & 58 & 10 & 0.04 & 0.4 & 0.1 & 6.9 & 0.09 & 30.0 & 0.06 \\
\hline & $15-30$ & 1.30 & 0.09 & 0.28 & 0.33 & 30 & 52 & 18 & 0.02 & 0.5 & 0.1 & 6.9 & 0.09 & 28.5 & 0.06 \\
\hline & $30-60$ & 1.40 & 0.12 & 0.28 & 0.33 & 23 & 56 & 21 & 0.01 & 0.7 & 0.3 & 6.9 & 0.12 & 48.0 & 0.04 \\
\hline & $60-90$ & 1.58 & 0.12 & 0.32 & 0.37 & 31 & 47 & 22 & 0.01 & 0.9 & 0.4 & 7.0 & 0.12 & 60.0 & 0.04 \\
\hline & $90-120$ & 1.76 & 0.12 & 0.33 & 0.34 & 31 & 47 & 22 & 0.01 & 0.9 & 0.2 & 7.5 & 0.12 & 63.0 & 0.03 \\
\hline \multirow[t]{5}{*}{ Melfort } & $0-15$ & 0.94 & 0.10 & 0.35 & 0.35 & 14 & 60 & 26 & 0.04 & 0.4 & 0.1 & 6.8 & 0.2 & 23.7 & 0.06 \\
\hline & $15-30$ & 1.36 & 0.10 & 0.31 & 0.31 & 12 & 52 & 36 & 0.02 & 0.5 & 0.1 & 7.0 & 0.27 & 31.4 & 0.06 \\
\hline & $30-45$ & 1.56 & 0.11 & 0.30 & 0.30 & 8 & 33 & 58 & 0.02 & 0.5 & 0.3 & 8.0 & 0.29 & 17.4 & 0.04 \\
\hline & $45-60$ & 1.60 & 0.16 & 0.40 & 0.40 & 4 & 23 & 73 & 0.02 & 0.5 & 0.3 & 8.0 & 0.32 & 11.7 & 0.04 \\
\hline & $60-120$ & 1.68 & 0.18 & 0.37 & 0.37 & 4 & 23 & 73 & 0.02 & 0.7 & 0.3 & 8.0 & 0.35 & 10.8 & 0.03 \\
\hline
\end{tabular}


by three latest sowing dates, including the initial sowing window (as used for model training), were considered for assessing the impacts of changing sowing windows on grain yield under the future climate scenarios. The possible earliest sowing dates were 20 April, 26 April, 2 May and 9 May, whereas the possible latest sowing dates were 24 May, 31 May and 7 June. Simulations were performed using each of the two RCPs over the 2030-2099 period. Trends in future simulated spring wheat yields were then assessed over three periods [i.e., the 2040s (2030-2049), 2060s (2050-2069), and 2080s (2070-2099)] using a 20-year baseline period (1990-2009) of observed yields.

The statistical indicators used for evaluating the performance of APSIM included the coefficient of determination $\left(\mathrm{R}^{2}\right)$, mean absolute error (MAE), root mean square error (RMSE) and the Willmott index of agreement (d; [32]).

The MAE measures the average magnitude of the errors in a set of forecasts, without considering their direction. It was calculated as follows:

$$
\mathrm{MAE}=\frac{1}{n} \sum_{i=1}^{n}\left|P_{i}-O_{i}\right|
$$

where $n$ is the number of observations, $P_{i}$ is the predicted yield or biomass, and $O_{i}$ is the observed yield or biomass.

The RMSE is one of the most widely used errors measures. It gives the weighted variations in errors between the predicted and observed values. It was calculated as follows:

$$
\mathrm{RMSE}=\sqrt{\frac{1}{n} \sum_{i=1}^{n}\left(P_{i}-O_{i}\right)^{2}}
$$

The d-index is a descriptive measure and has values ranging from 0 to 1 . The higher the index value the better the model performance. Its formula is as follows:

$$
d=1-\left[\sum_{i=1}^{n}\left(P_{i}-O_{i}\right)^{2} / \sum_{i=1}^{n}\left(\left|P_{i}-\bar{O}\right|+\left|O_{i}-\bar{O}\right|\right)^{2}\right]
$$

where $\bar{O}$ is the average value of observed yields.

\section{Results and Discussion}

\subsection{Variability of Weather Conditions during the Growing Period}

Figure 1 and Figure 2 show temperatures and rainfall patterns at the study sites during the cropping season (May-September) for the historical period and future climate scenarios. At both sites, there was a decreasing trend in average maximum temperatures over the 1949/1961-2009 period. The variability in average maximum temperatures during the cropping season was more pronounced than that in average minimum temperatures over that period at all sites. Average maximum temperatures over the cropping season ranged from $19^{\circ} \mathrm{C}$ to $28^{\circ} \mathrm{C}$ and $18^{\circ} \mathrm{C}$ to $26^{\circ} \mathrm{C}$ at Swift Current and Melfort, respectively. The respective ranges of average minimum temperatures were from $7^{\circ} \mathrm{C}$ to $11^{\circ} \mathrm{C}$ and $6^{\circ} \mathrm{C}$ to $11^{\circ} \mathrm{C}$. However, a trend of increasing average minimum and maximum temperatures was observed for both future climate scenarios at both sites over the 2030-2099 period, with higher average temperatures more noticeable by the end of the century (Figure 1). The increase in average temperature was less obvious between the two RCPs during the 2040s and 2060s; but became more marked by the end of the century, namely at Swift Current.

Regarding the total rainfall during the cropping season (Figure 2), increases would be expecting over 2030-2099, compared to historical data. Over the historical period at both sites, the total rainfall barely was $>300 \mathrm{~mm}$ (average value of $\sim 250 \mathrm{~mm}$ and minimum $<100 \mathrm{~mm}$ ). Whilst in future climate scenarios, the total rainfall over the cropping seasons was $>310 \mathrm{~mm}$ on average, regardless of the RCP considered, with peaks reaching $610 \mathrm{~mm}$ (RCP4.5) and $750 \mathrm{~mm}$ (RCP8.5) at Swift Current. At Melfort the maximum total rainfall during the cropping seasons would reach $540 \mathrm{~mm}$ and $600 \mathrm{~mm}$ in case of RCP4.5 and RCP8.5, respectively.

\subsection{Calibration and Validation of APSIM at the Selected Sites}

Simulated grain yield, total above-ground biomass, and anthesis and physiologic maturity dates were compared 


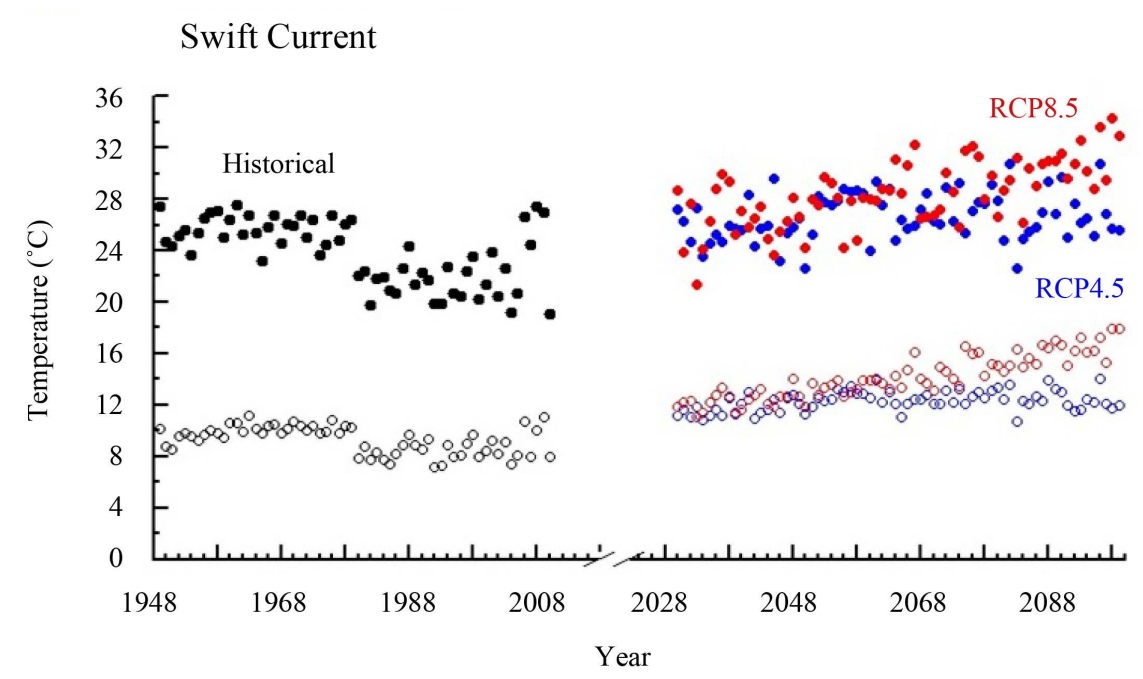

(a)

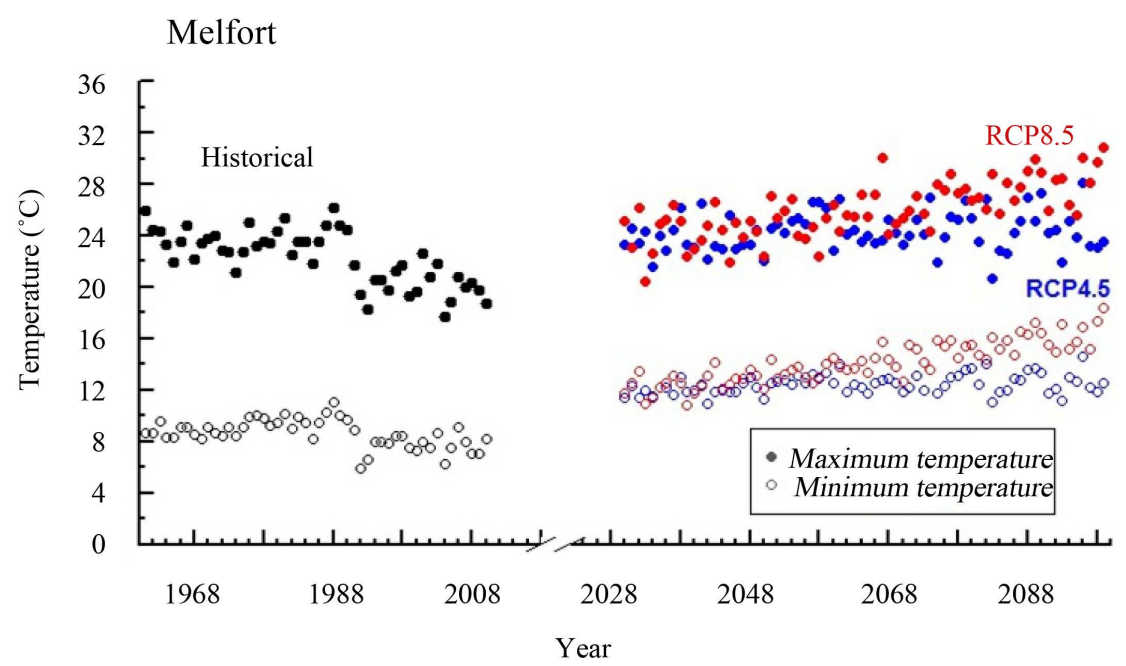

(b)

\begin{abstract}
Figure 1. Average cropping season (May-September) maximum (filled circles) and minimum (open circles) temperatures at Swift Current (a) and Melfort (b), Western Canada. Historical climate data (black circles) are related to the period of availability of spring wheat yield at plot level and spanned the 1949-2009 and 1961-2009 periods for Swift Current and Melfort, respectively. Future climate scenarios were derived from the CanRCM4 model forced with concentrations following the medium emission scenario (RCP4.5, blue circles) and the high emission scenario (RCP8.5, red circles).
\end{abstract}

to the observed ones at Swift Current during the 1998-2001 period (Table 3) during the model training phase.

Anthesis and physiologic maturity dates were satisfactorily captured by the model depending on the year. Differences between dates ranged from 1 day to 11 days, and 4 days to 9 days, respectively for anthesis and physiologic maturity. Moreover, the comparison between predicted and observed grain yield and biomass resulted in $\mathrm{R}^{2}>0.80$ in both crop variables. The spring wheat yield was simulated with RMSE of $684 \mathrm{~kg} / \mathrm{ha}$ and MAE of $476 \mathrm{~kg} / \mathrm{ha}$. Based on simulations including five sites in Saskatchewan (including Swift Current) and Manitoba, Mkhabela and Bullock (2012) [30] reported RMSE and MAE values of $743 \mathrm{~kg} / \mathrm{ha}$ and $611 \mathrm{~kg} / \mathrm{ha}$, respectively, when simulating spring wheat yieldusing the AquaCrop model. Although the periods of simulation were different (2003-2006 in [30]), the same range of model performance can be attained through the APSIM model.

A robustness test of APSIM was then carried out based on long time series data of spring wheat yield at Swift 


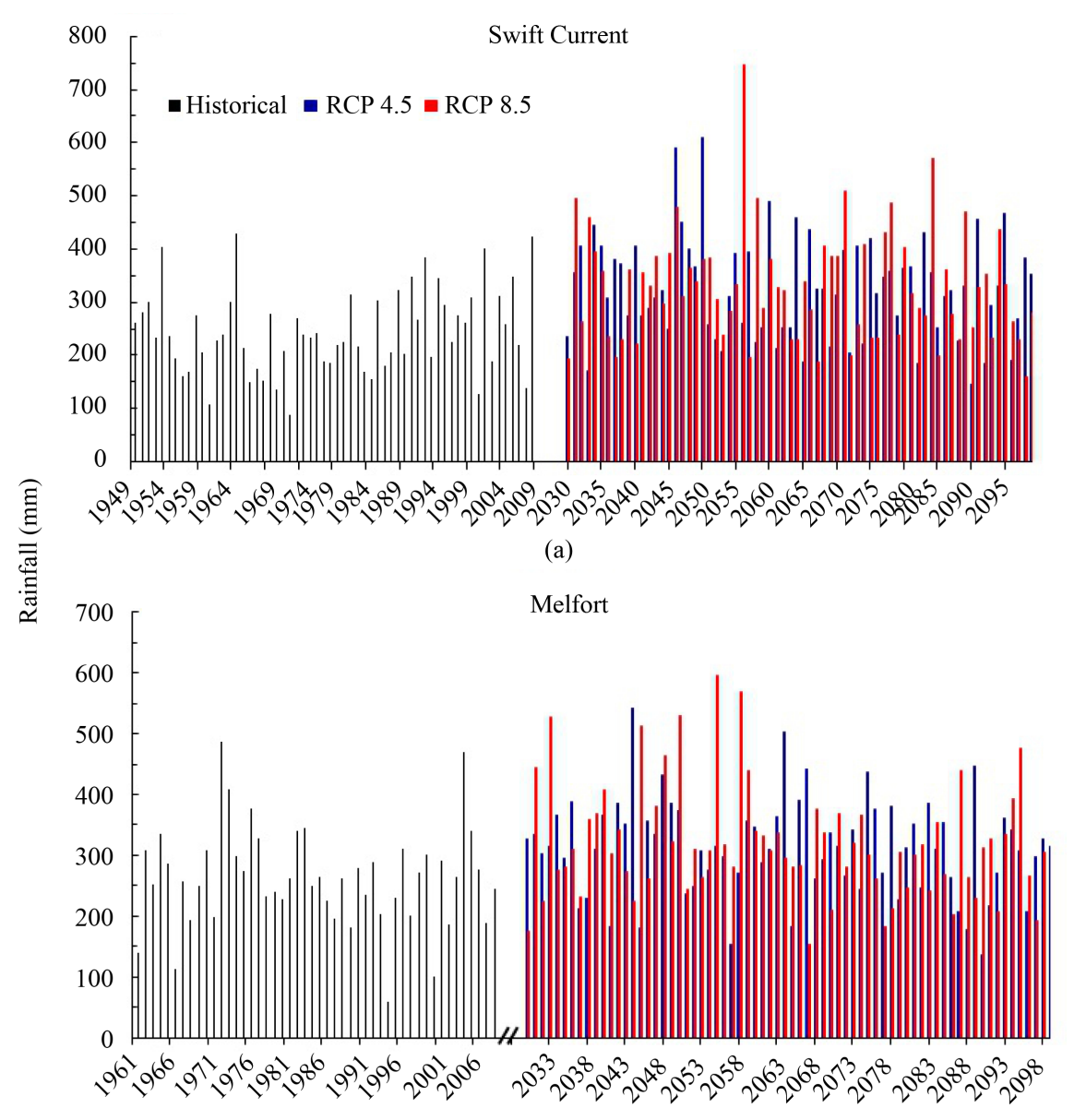

(b)

Figure 2. Total rainfall over the cropping season (May-September) at Swift Current (a) and Melfort (b), Western Canada. Historical climate data (black bars) are related to the period of availability of spring wheat at plot level and spanned the 1949-2009 and 1961-2009 periods for Swift Current and Melfort, respectively. Future climate scenarios were derived from the CanRCM4 model forced with concentrations following the medium emission scenario (RCP4.5, blue bars) and the high emission scenario (RCP8.5, red bars).

Table 3. APSIM performance during the calibration phase: observed and simulated anthesis and physiologic maturity dates of spring wheat, and selected statistical indicators of model performance. Data from experimental plots at Swift Current were used for the calibration purpose.

\begin{tabular}{cccccccc}
\hline \multicolumn{7}{c}{$\begin{array}{c}\text { Anthesis Date } \\
\text { (Days after Planting, DAP) }\end{array}$} & \multicolumn{2}{c}{$\begin{array}{c}\text { Physiologic Maturity Date } \\
\text { (DAP) }\end{array}$} & $\begin{array}{c}\text { Statistical } \\
\text { Indicators }\end{array}$ & Yield & Biomass \\
\hline Year & Observed & Simulated & Observed & Simulated & & & \\
\hline 1998 & 73 & 62 & 103 & 96 & & 0.86 & 0.87 \\
1999 & 69 & 73 & 101 & 110 & $\mathrm{R}^{2}$ & 476 & 1146 \\
2000 & 70 & 69 & 101 & 105 & MAE (kg/ha) & 684 & 1373 \\
2001 & 66 & 60 & 100 & 94 & RMSE (kg/ha) & 6 & \\
\hline
\end{tabular}

Current and Melfort. Comparisons between observed and predicted yields resulted in MAE, RMSE and d values of $492 \mathrm{~kg} / \mathrm{ha}, 1000 \mathrm{~kg} / \mathrm{ha}$ and 0.74 , respectively, for Swift Current. The values were $603 \mathrm{~kg} / \mathrm{ha}, 1196 \mathrm{~kg} / \mathrm{ha}$ and 0.75 , respectively for MAE, RMSE, and d at Melfort.

When data from the two sites were pooled, the overall robustness was quite satisfactory (Figure 3). The MAE an RMSE were respectively $529 \mathrm{~kg} / \mathrm{ha}$ and $1023 \mathrm{~kg} / \mathrm{ha}(\mathrm{d}=0.80)$. The relatively high RMSE at both sites could 


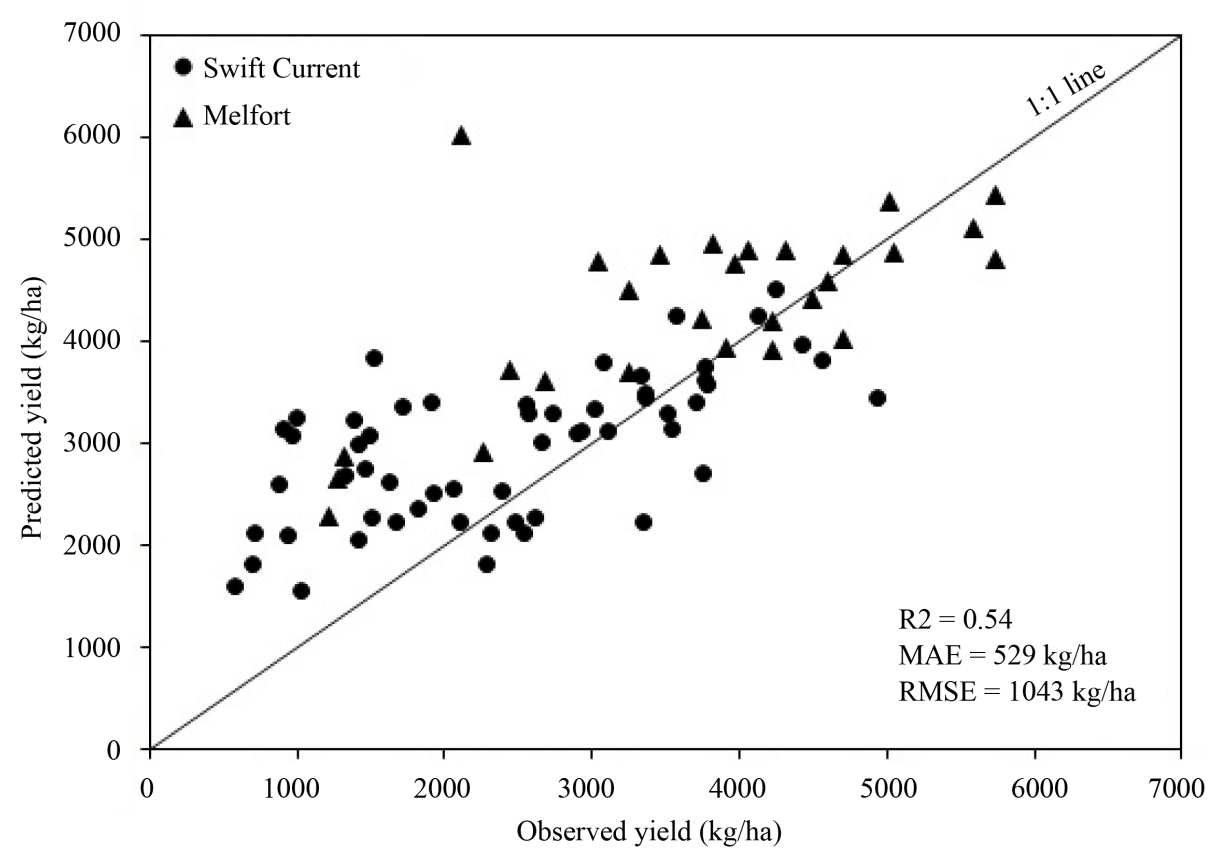

Figure 3. Relationships between observed and predicted yields during the robustness test of APSIM at two selected sites in Saskatchewan, Canada.

be explained by the differences in cultivars over the period considered (Table 1). Indeed, the calibration was performed based on data involving cultivar AC Barrie, which is a higher grain yield variety compared to the two others [33]. Therefore, the model tended to overestimate the yield during periods with different cultivars. Furthermore, the configuration of simulations were kept the same over the entire period and may not well reflect the management practices in all cropping seasons. Other reasons include the fact simulations were performed in "potential" mode, i.e., weeds, disease or insects do not affect growth or yield. In Canadian Prairies wheat yield loss due to pest and diseases can reach approximately $20 \%$ each year [34].

A probabilistic forecasting tool, the Integrated Canadian Crop Yield Forecaster (ICCYF, which integrates agroclimate variables and remote sensing indices), has been developed for generating yield forecasts at the seasonal and regional-scale of major grain crops in Canada [35] [36]. Thus, APSIM-generated scenarios at selected validation sites across Canada (based on available and adequate data) could be potentially integrated as an additional supporting index included with the new ICCYF crop outlooks.

\subsection{Impact of Change in Sowing Windows on Spring Wheat Yields}

Under the projected climate conditions and the criteria defined for simulations, simulated sowing dates were almost in the same range for a given fixed earliest possible date and varying latest possible date, irrespective of the period considered (Figure 4). For both RCPs at Swift Current, simulated sowing dates were more variable during the 2060s compared to other periods. Total rainfall during the cropping season during this period was relatively high on average (Figure 2), and could explain such variability in sowing dates simulated by the model. At Melfort, regardless of the predefined sowing windows, a narrow variation generally was found for projected climate conditions under RCP8.5. A relatively high variability was found in most cases under RCP4.5. Furthermore, the closeness of the median value of sowing dates to the first quartile in the distribution (confounded to the first quartile in most cases, Figure 4) reveals that the model set the sowing dates at the start of the sowing window in $25 \%-50 \%$ of cases, that is the predefined conditions for sowing would be met earlier in the sowing period.

Table 4 gives the potential impacts of tested sowing windows on the final yield were explored. Overall, spring wheat yields negatively would be affected by the variability in climate at the study sites without adaptation strategies. Variations from a 1990-2009 baseline period of simulated yields using APSIM ranged from -24\% to $-94 \%$ depending on the site, RCP, and period considered. Highest negative changes were observed for 


\section{Swift Current}

2030-2049
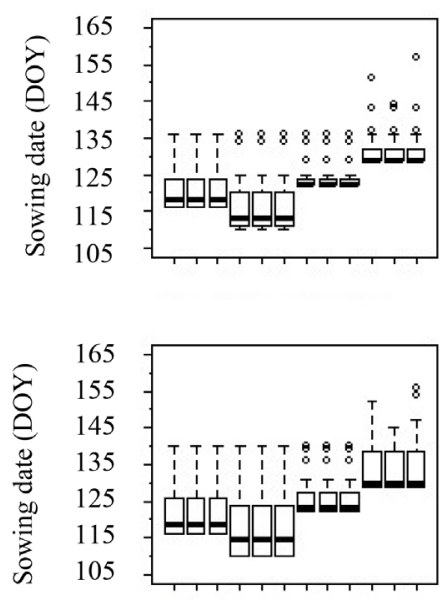

$\begin{array}{llll}\mathrm{S} 1 & \mathrm{~S} 4 & \mathrm{~S} 7 & \mathrm{~S} 10\end{array}$

Melfort

2030-2049
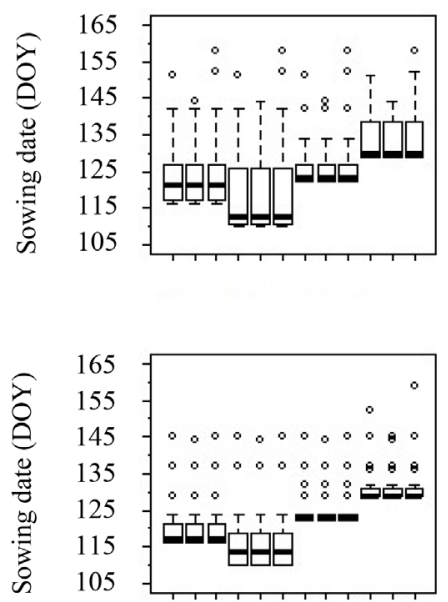

$\begin{array}{llll}\mathrm{S} 1 & \mathrm{~S} 4 & \mathrm{~S} 7 & \mathrm{~S} 10\end{array}$
2050-2069
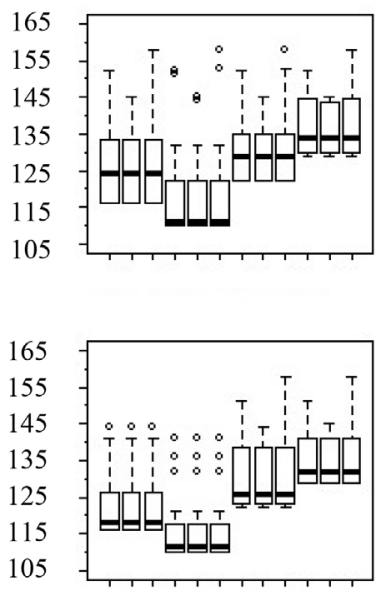

$\begin{array}{llll}\text { S1 } & \text { S4 } & \text { S7 } & \text { S10 }\end{array}$
2070-2099
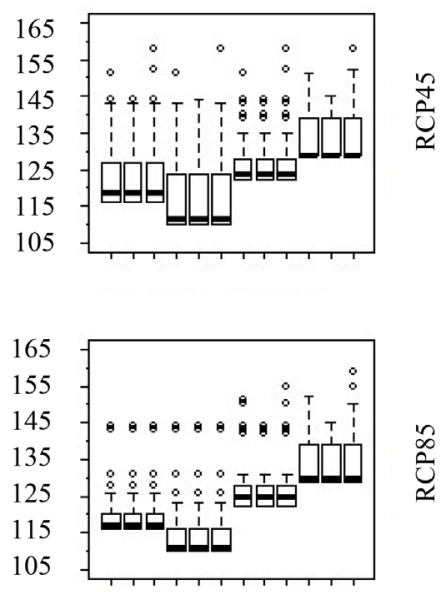

$\begin{array}{llll}\text { S1 } & \text { S4 } & \text { S7 } & \text { S10 }\end{array}$
2050-2069
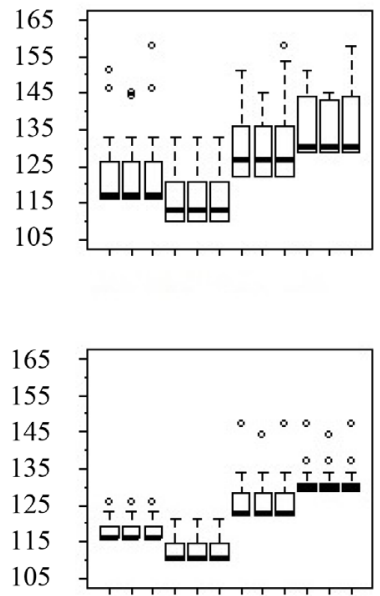

$\begin{array}{llll}\text { S1 } & \text { S4 } & \text { S7 } & \text { S10 }\end{array}$
2070-2099
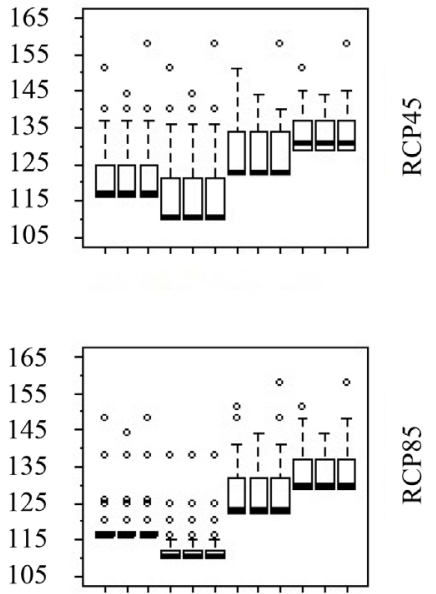

$\begin{array}{llll}\mathrm{S} 1 & \mathrm{~S} 4 & \mathrm{~S} 7 & \mathrm{~S} 10\end{array}$

Figure 4. Distribution of the sowing dates (day of year, DOY) simulated by the APSIM model according to predefined sowing windows at Swift Current (upper) and Melfort (bottom). Simulations were performed using projected climate data under two scenarios RCP4.5 and RCP8.5. Sowing windows S1-S12 are (earliest possible date-lastest possible date) 26 April-31 May, 26 April-24 May, 26 April-7 June, 20 April-31 May, 20 April-24 May, 20 April-7 June, 2 May-31 May, 2 May-24 May, 2 May-7 June, 9 May-31 May, 9 May-24 May, and 9 May-7 June, respectively. The ends of the boxplots indicate the upper and lower quantiles, the median is the solid line in the box. The whiskers indicate the minimum and maximum values.

sowing occurring during 9 May and 7 June. An increasing trend in yield loss ( $>10 \%$ on average) was observed when the possible earliest sowing date was fixed late in the season (i.e., from 20 April to 9 May, at a weekly time step), regardless of the period at both sites. However, for a fixed earliest possible sowing date the latest possible sowing date generally did not affect the percentage of change (Table 4). Comparing the sites between them, changes in climate patterns and sowing windows affected differently final grain yields of spring wheat, with highest losses being recorded at Melfort. Indeed, they ranged from the 2060s to the 2080s ranged from $14 \%$ to $17 \%$ and $27 \%$ to $32 \%$ for RCP 4.5 and RCP 8.5 , respectively at Melfort. Whereas at Swift Current the respective 
Table 4. Mean potential changes in spring wheat grain yield (expressed in \%) according to different sowing windows at Melfort and Swift Current, Canada. Comparisons were based on simulated yield using the APSIM model. The baseline period of observed yields was 1990-2009. Future climate scenarios based on RCP 4.5 and RCP 8.5 were considered.

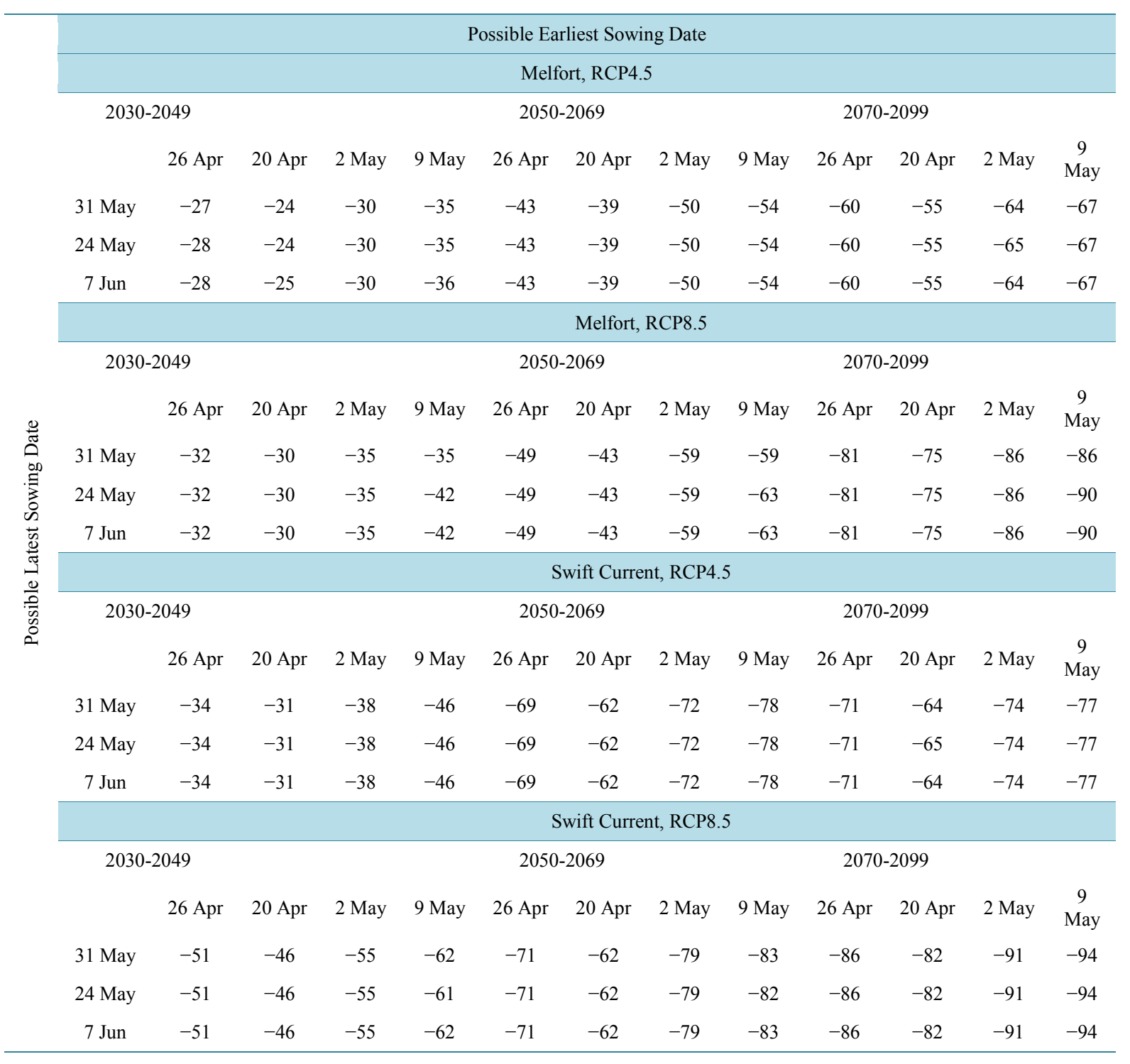

ranges were $1 \%$ to $3 \%$ and $12 \%$ to $20 \%$ over the same periods. The northern site was thus more vulnerable to changes in climate conditions. The combined effects of lower rainfall and relatively low temperatures, compared to the southern site (i.e., Swift Current), may adversely impact the final grain yield.

At both sites, the benefit of increased rainfall during the cropping season may have been offset by factors such as the evaporative demand [37]. Overall, the sowing windows that led to lower yield losses during the three periods (2040s, 2060s and 2080s) were those with an earliest possible sowing date of 20 April. These results support the conclusions of [5] who reported that farmers could have the potential of earlier seeding under projected climate change in Saskatchewan. When using APSIM to assess the impacts of projected changes in rainfall, temperature and $\mathrm{CO}_{2}$, Potgieter et al. (2013) [38] also reported an increased proportion of early sown wheat across a North-South transect in Eastern Australia. The effect of increased $\mathrm{CO}_{2}$ under future climate scenario was not included in our analysis since it did not affect the sowing date within APSIM. However, when included into crop growth simulation, that effect might positively influence the final grain yield of spring wheat under such scenarios [19] [38].

Our simulations were based on only one general circulation climate model (CanESM2), and the results should 
be interpreted accordingly as results from ensemble climate models may be preferred for such studies (broad simulation context and model uncertainties taken into account in ensemble models). Nevertheless, the trend of the impact of changes in future climate on wheat production in Western Canada was reasonably captured. Across Canada, projected climate changes would affect negatively the productivity of major crops including spring wheat [21]. Although increases of total rainfall over the cropping season will be expected, based on the CanESM2 outputs (Figure 2), the negative trend observed in final yields compared to the baseline period average yield can be related to the water availability during sensitive growing periods of spring wheat. Water availability during sensitive phenological stages (not explored here) can affect adversely the final grain yield. In APSIM grain yield loss due to the effects of water deficit during sensitive phenological stages can reach $40 \%$ depending on the duration of the deficit and the timing [39] [40]. Given the absence of measured data at the sowing time the initial water availability was assumed to be $>70 \%$ of field capacity in our study at both sites. This also could have played a role in the trend observed in simulated yields. Furthermore, extremely low or high temperatures throughout the growing season can suppress the crop growth (sometimes by killing the crops) [41]. Such impacts will be further investigated to get more insights on what proportion spring wheat yield losses would be under projected climate conditions.

\section{Conclusion}

A performance analysis of the APSIM model was conducted at two sites in the Province of Saskatchewan in Canada based on spring wheat yield data from long term experimental plots. Although the period involved wheat cultivars with different traits, reasonable grain yield simulations could be obtained with a model calibration based on the latest cultivar $(\mathrm{RMSE}=684 \mathrm{~kg} / \mathrm{ha} ; \mathrm{MAE}=476 \mathrm{~kg} / \mathrm{ha}$ ). The robustness test of the model based on long time series of observed data resulted in MAE $=529 \mathrm{~kg} / \mathrm{ha}$ and RMSE $=1043 \mathrm{~kg} / \mathrm{ha}$ (Willmott index of agreement $=0.80$ ). Relying on this evaluation, a sensitivity analysis of the impact of change in sowing windows on final yield was then performed under projected climate conditions (RCP4.5 and RCP8.5) over the period 2030-2099. A general trend in spring wheat yield loss from a baseline of 1990-2009 was observed regardless of the sowing window and the RCP, with a range from $-24 \%$ to $-94 \%$ depending on the site. Smallest yield losses could be obtained through earlier possible sowing date (i.e., mid-April) under the projected future climate conditions. Although the simulations were based on only one general circulation climate model (the CanESM2 model), the trend in spring wheat yield changed was well captured by APSIM under projected climate conditions at both sites. Our findings could therefore serve as a basis for using APSIM as a decision support tool for adaptation/mitigation options under possible climate variability across Western Canada.

\section{Acknowledgements}

We thank the Growing Forward II Program and Sustainability Metrics Project of Agriculture and Agri-Food Canada (AAFC) and the National Science and Engineering Council of Canada (NSERC)'s Visiting Fellows in Government Laboratories Program for providing funding support. We also thank Dr. Hong Wang and Dr. Brian McConkey (AAFC-Swift Current) for providing the long-term crop rotation experimental data.

\section{References}

[1] Challinor, A.J., Ewert, F., Arnold, S., Simelton, E. and Fraser, E. (2009) Crops and Climate Change: Progress, Trends, and Challenges in Simulating Impacts and Informing Adaptation. Journal of Experimental Botany, 60, 2775-2789. http://dx.doi.org/10.1093/jxb/erp062

[2] van Ittersum, M.K. and Donatelli, M. (2003) Modelling Cropping Systems-Highlights of the Symposium and Preface to the Special Issues. European Journal of Agronomy, 18, 187-197. http://dx.doi.org/10.1016/S1161-0301(02)00095-3

[3] Rosenzweig, C., Jones, J.W., Hatfield, J.L., et al. (2013) The Agricultural Model Intercomparison and Improvement Project (AgMIP): Protocols and Pilot Studies. Agricultural and Forest Meteorology, 170, 166-182. http://dx.doi.org/10.1016/j.agrformet.2012.09.011

[4] Rosenzweig, C., Elliott, J., Deryng, D., et al. (2014) Assessing Agricultural Risks of Climate Change in the 21st Century in a Global Gridded Crop Model Intercomparison. Proceedings of the National Academy of Sciences, 111, 32683273. http://dx.doi.org/10.1073/pnas. 1222463110

[5] He, Y., Wang, H., Qian, B., McConkey, B. and DePauw, R. (2012) How Early Can the Seeding Dates of Spring Wheat Be Under Current and Future Climate in Saskatchewan, Canada? PLoS ONE, 7, e45153. 
http://dx.doi.org/10.1371/journal.pone.0045153

[6] Jones, J.W., Hoogenboom, G., Porter, C.H., et al. (2003) The DSSAT Cropping System Model. European Journal of Agronomy, 18, 235-265. http://dx.doi.org/10.1016/S1161-0301(02)00107-7

[7] Keating, B.A., Carberry, P.S., Hammer, G.L., et al. (2003) An Overview of APSIM, A Model Designed for Farming Systems Simulation. European Journal of Agronomy, 18, 267-288. http://dx.doi.org/10.1016/S1161-0301(02)00108-9

[8] Kouadio, L. and Newlands, N. (2015) Building Capacity for Assessing Spatial-Based Sustainability Metrics in Agriculture. Decision Analytics, 2, 2. http://dx.doi.org/10.1186/s40165-015-0011-9

[9] Jones, J.W., Antle, J.M., Basso, B.O., et al. (2015) Towards a New Generation of Agricultural System Models, Data, and Knowledge Products: State of Agricultural Systems Science.

https://www.agmip.org/refbase/uploads/jones/2015/219 Jones2015.pdf

[10] van Ittersum, M.K., Ewert, F., Heckelei, T., et al. (2008) Integrated Assessment of Agricultural Systems-A Component-Based Framework for the European Union (SEAMLESS). Agricultural Systems, 96, 150-165. http://dx.doi.org/10.1016/j.agsy.2007.07.009

[11] Asseng, S., Ewert, F., Rosenzweig, C., Jones, J.W., Hatfield, J.L., Ruane, A.C., et al. (2013) Uncertainty in Simulating Wheat Yields Under Climate Change. Nature Climate Change, 3, 827-832. http://dx.doi.org/10.1038/nclimate1916

[12] FAO (2014) FAOSTAT. Crops, National Production, FAO, Rome.

[13] Touré, A., Major, D.J. and Lindwall, C.W. (1995) Sensitivity of Four Wheat Simulation Models to Climate Change. Canadian Journal of Plant Science, 75, 69-74. http://dx.doi.org/10.4141/cips95-011

[14] Ritchie, J.T. and Otter, S. (1985) Description and Performance of CERES-Wheat: A User-Oriented Wheat Yield Model. In: ARS Wheat Yield Project, ARS-38, Natural Technology Information Service, Springfield, 159-175.

[15] Williams, J.R. (1983) EPIC, The Erosion-Productivity Impact Calculator, Volume 1. Model Documentation, Technical Bulletin Number 1768, Agricultural Research Service, United States Department of Agriculture, 377.

[16] Stewart, D.W. and Dwyer, L.M. (1990) A Model of Spring Wheat (Triticum aestivum) for Large Area Yield Estimations on the Canadian Prairies. Canadian Journal of Plant Science, 70, 19-32. http://dx.doi.org/10.4141/cjps90-003

[17] Amir, J. and Sinclair, T.R. (1991) A Model of the Temperature and Solar-Radiation Effects on Spring Wheat Growth and Yield. Field Crops Research, 28, 47-58. http://dx.doi.org/10.1016/0378-4290(91)90073-5

[18] McFarlane, N.A., Boer, G.J., Blanchet, J.P. and Lazare, M. (1992) The Canadian Climate Centre Second-Generation General Circulation Model and Its Equilibrium Climate. Journal of Climate, 5, 1013-1044. http://dx.doi.org/10.1175/1520-0442(1992)005<1013:TCCCSG>2.0.CO;2

[19] Qian, B., De Jong, R., Huffman, T., Wang, H. and Yang, J. (2015) Projecting Yield Changes of Spring Wheat under Future Climate Scenarios on the Canadian Prairies. Theoretical and Applied Climatology, 1-19. http://dx.doi.org/10.1007/s00704-015-1378-1

[20] IPCC (2000) Emissions Scenarios IPCC Special Report. Cambridge University Press, Cambridge.

[21] IPCC (2014) Climate Change 2014: Impacts, Adaptation, and Vulnerability. Part A: Global and Sectoral Aspects. Contribution of Working Group II to the Fifth Assessment Report of the Intergovernmental Panel on Climate Change. Cambridge University Press, Cambridge, UK and New York. 1-32.

[22] Spokas, K. and Forcella, F. (2006) Estimating Hourly Incoming Solar Radiation from Limited Meteorological Data. Weed Science, 54, 182-189. http://dx.doi.org/10.1614/WS-05-098R.1

[23] Kahimba, F.C., Bullock, P.R., Sri Ranjan, R. and Cutforth, H.W. (2009) Evaluation of the Solarcalc Model for Simulating Hourly and Daily Incoming Solar Radiation in the Northern Great Plains of Canada. Canadian Biosystems Engineering/Le génie des biosystèmes au Canada, 51, 1.11-1.21.

[24] von Salzen, K., Scinocca, J.F., McFarlane, N.A., Li, J.N., Cole, J.N.S., Plummer, D., et al.(2013) The Canadian Fourth Generation Atmospheric Global Climate Model (CanAM4). Part I: Representation of Physical Processes. AtmosphereOcean, 51, 104-125. http://dx.doi.org/10.1080/07055900.2012.755610

[25] Diaconescu, E., Gachon, P., Scinocca, J. and Laprise, R. (2014) Evaluation of Daily Precipitation Statistics and Monsoon Onset/Retreat over Western Sahel in Multiple Data Sets. Climate Dynamics, 1-30. http://dx.doi.org/10.1007/s00382-014-2383-2

[26] Arora, V.K. and Boer, G.J. (2010) Uncertainties in the 20th Century Carbon Budget Associated with Land Use Change. Global Change Biology, 16, 3327-3348. http://dx.doi.org/10.1111/j.1365-2486.2010.02202.x

[27] Chylek, P., Li, J., Dubey, M.K., Wang, M. and Lesins, G. (2011) Observed and Model Simulated 20th Century Arctic Temperature Variability: Canadian Earth System Model CanESM2. Atmospheric Chemistry and Physics Discussions, 11, 22893-22907. http://dx.doi.org/10.5194/acpd-11-22893-2011

[28] IPCC (2013) Climate Change 2013: The Physical Science Basis. Contribution of Working Group I to the Fifth As- 
sessment Report of the Intergovernmental Panel on Climate Change. Cambridge University Press, Cambridge, UK and New York.

[29] Wang, H., Mc Caig, T.N., De Pauw, R.M., Clarke, F.R. and Clarke, J.M. (2002) Physiological Characteristics of Recent Canada Western Red Spring Wheat Cultivars: Yield Components and Dry Matter Production. Canadian Journal of Plant Science, 82, 299-306. http://dx.doi.org/10.4141/P01-107

[30] Mkhabela, M.S. and Bullock, P.R. (2012) Performance of the FAO AquaCrop Model for Wheat Grain Yield and Soil Moisture Simulation in Western Canada. Agricultural Water Management, 110, 16-24. http://dx.doi.org/10.1016/j.agwat.2012.03.009

[31] Chipanshi, A.C., Ripley, E.A. and Lawford, R.G. (1999) Large-Scale Simulation of Wheat Yields in a Semi-Arid Environment Using a Crop-Growth Model. Agricultural Systems, 59, 57-66. http://dx.doi.org/10.1016/S0308-521X(98)00082-1

[32] Willmott, C.J. (1982) Some Comments on the Evaluation of Model Performance. Bulletin American Meteorological Society, 63, 1309-1313. http://dx.doi.org/10.1175/1520-0477(1982)063<1309:SCOTEO >2.0.CO;2

[33] McCaig, T.N., DePauw, R.M., Clarke, J.M., McLeod, J.G., Fernandez, M.R. and Knox, R.E. (1996) AC Barrie Hard Red Spring Wheat. Canadian Journal of Plant Science, 76, 337-339. http://dx.doi.org/10.4141/cjps96-059

[34] Galushko, V. and Gray, R. (2008) Benefits from Wheat Breeding Research in Western Canada. Canadian Agricultural Innovation Research Network.

http://www.ag-innovation.usask.ca/Publications for\%20Download/Wheat rateofreturn Galushko and Gray 2008.pdf

[35] Newlands, N.K., Zamar, D.S., Kouadio, L.A., et al. (2014) An Integrated, Probabilistic Model for Improved Seasonal Forecasting of Agricultural Crop Yield under Environmental Uncertainty. Frontiers in Environmental Science, 2, 1-21. http://dx.doi.org/10.3389/fenvs.2014.00017

[36] Chipanshi, A., Zhang, Y., Kouadio, L., Newlands, N., Davidson, A., Hill, H., et al.(2015) Evaluation of the Integrated Canadian Crop Yield Forecaster (ICCYF) Model for In-Season Prediction of Crop Yield across the Canadian Agricultural Landscape. Agricultural and Forest Meteorology, 206, 137-150. http://dx.doi.org/10.1016/j.agrformet.2015.03.007

[37] Qian, B., Zhang, X., Chen, K., Feng, Y. and O’Brien, T. (2009) Observed Long-Term Trends for Agroclimatic Conditions in Canada. Journal of Applied Meteorology and Climatology, 49, 604-618. http://dx.doi.org/10.1175/2009JAMC2275.1

[38] Potgieter, A., Meinke, H., Doherty, A., Sadras, V.O., Hammer, G., Crimp, S. and Rodriguez, D. (2013) Spatial Impact of Projected Changes in Rainfall and Temperature on Wheat Yields in Australia. Climatic Change, 117, 163-179. http://dx.doi.org/10.1007/s10584-012-0543-0

[39] Asseng, S., Jamieson, P.D., Kimball, B., Pinter, P., Sayre, K., Bowden, J.W. and Howden, S.M. (2004) Simulated Wheat Growth Affected by Rising Temperature, Increased Water Deficit and Elevated Atmospheric $\mathrm{CO}_{2}$. Field Crops Research, 85, 85-102. http://dx.doi.org/10.1016/S0378-4290(03)00154-0

[40] Saseendran, S.A., Ahuja, L.R., Ma, L., et al. (2008) Current Water Deficit Stress Simulations in Selected Agricultural System Models. In: Ahuja, L.R., Reddy, V.R., Saseendran, S.A. and Yu, Q., Eds., Advances in Agricultural Systems Modeling, Response of Crops to Limited Water: Understanding and Modeling Water Stress Effects on Plant Growth Processes, American Society of Agronomy, Crop Science Society of America, Soil Science Society of America, Madison, 1-38. http://dx.doi.org/10.2134/advagricsystmodel1.c1

[41] Porter, J.R. and Gawith, M. (1999) Temperatures and the Growth and Development of Wheat: A Review. European Journal of Agronomy, 10, 23-36. http://dx.doi.org/10.1016/S1161-0301(98)00047-1 